\title{
Novos táxons de Lamiinae (Coleoptera, Cerambycidae) da América do Sul
}

\author{
Maria Helena M. Galileo ${ }^{1} \&$ Ubirajara R. Martins ${ }^{2}$
}

1. Museu de Ciências Naturais, Fundação Zoobotânica do Rio Grande do Sul. Rua Dr. Salvador França, 1427, 90690-000, Porto Alegre, RS, Brasil. (galileo@fzb.rs.gov.br)
2. Museu de Zoologia, Universidade de São Paulo, Caixa Postal 42594, 04218-970, São Paulo, SP, Brasil. (urmsouza@usp.br)

ABSTRACT. New taxa of Lamiinae (Coleoptera, Cerambycidae) from South America. New taxa described: Acanthoderini, Nesozineus
osorioensis sp. nov., from Brazil (Rio Grande do Sul); Calliini, Drycothaea clara sp. nov., from Brazil (Rondônia) and Drycothaea hovorei sp.
nov., from Ecuador (Napo); Forsteriini, Itacolomi gen. nov., type-species I. letiziae sp. nov., from Brazil (Minas Gerais); Yapyguara, gen. nov.,
type-species Y. fusca sp. nov., from Bolivia (Santa Cruz); Xenofreini, Xenofrea zischkai sp. nov., from Ecuador (Napo) and Bolivia (Santa Cruz).

KEYWORDS. Acanthoderini, Calliini, Forsteriini, taxonomy, Xenofreini.

RESUMO. Novos táxons descritos: Acanthoderini, Nesozineus osorioensis sp. nov., do Brasil (Rio Grande do Sul); Calliini, Drycothaea clara sp. nov., do Brasil (Rondônia) e Drycothaea hovorei sp. nov., do Equador (Napo); Forsteriini, Itacolomi gen. nov., espécie-tipo I. letiziae sp. nov., do Brasil (Minas Gerais); Yapyguara gen. nov., espécie-tipo Y. fusca sp. nov., da Bolívia (Santa Cruz); Xenofreini, Xenofrea zischkai sp. nov., do Equador (Napo) e da Bolívia (Santa Cruz).

PALAVRAS-CHAVE. Acanthoderini, Calliini, Forsteriini, taxonomia, Xenofreini.

Com base em material recebido para identificação de diversas coleções, descrevemos dois gêneros novos na tribo Forsteriini, duas espécies novas em Drycothaea Thomson, 1868 (Calliini), uma em Nesozineus Linsley \& Chemsak, 1966 (Acanthoderini) e uma em Xenofrea Bates, 1885 (Xenofreini).

Forsteriini reúne, atualmente, 14 gêneros sulamericanos (exceto Nyctonympha taeniata Martins \& Galileo, 1992 do Panamá e Trinidad e Tobago). Na tribo Calliini, Drycothaea agrupa 24 espécies e, recentemente, GALILEO \& MARTins (2010) publicaram uma chave para as 22 espécies da América continental. Em Acanthoderini, o gênero Nesozineus foi revisto por Galileo \& Martins (1996) quando foi elaborada uma chave para as 18 espécies conhecidas na época; outras sete espécies foram descritas por Galileo \& Martins (2006; 2007), Martins et al. (2009) e Martins \& Galileo (2010). Em Xenofreini, Xenofrea reúne 50 espécies e a única chave, apresentada por Galileo \& MARTINS (2005), é restrita a 13 espécies.

As siglas mencionadas no texto correspondem a: ACMS, American Coleoptera Museum, San Antonio, EUA; CASC, California Academy of Sciences, San Francisco, EUA; MNKM, Museo Noel Kempff Mercado, Santa Cruz, Bolívia; MZSP, Museu de Zoologia, Universidade de São Paulo, São Paulo, Brasil; RCSZ, Coleção Robin Clarke/ Sonia Zamalloa, Buena Vista, Bolívia.

\section{Acanthoderini \\ Nesozineus osorioensis sp. nov.} (Fig. 1)

Etimologia. O nome específico refere-se ao município de Osório, Rio Grande do Sul.

Cabeça com tegumento castanho-avermelhado, revestida por pubescência esbranquiçada, mais adensada entre os tubérculos anteníferos e ao redor dos lobos oculares superiores; pontuação subgrossa, esparsa. Lobos oculares superiores com cinco fileiras de omatídios; distância entre os lobos oculares superiores igual ao triplo da largura de um lobo. Antenas atingem os ápices elitrais, aproximadamente, na ponta do antenômero XI. Antenômeros basais com pubescência esbranquiçada; no dorso do escapo, pubescência mais densa.

Protórax com tegumento castanho-avermelhado. Lados do protórax com espinho pós-mediano manifesto, ápice voltado para trás; curvatura do terço basal acentuada. Pronoto densamente pontuado com gibosidades arredondadas no topo; pubescência esbranquiçada, mais densa numa faixa central irregular, intercalada por mancha de pubescência amarelada, no centro; lado interno dos espinhos, com área de pubescência mais adensada. Lados do protórax e esternos torácicos com pubescência esbranquiçada, densa. Escutelo, com pubescência esbranquiçada, densa, junto aos ângulos anteriores.

Élitros castanho-avermelhados; cada um com faixa de pubescência esbranquiçada, densa, junto à sutura da base ao meio, que se estende obliquamente até as margens pouco antes do terço apical, onde se alarga e reveste toda a superfície; pequenas manchas esparsas de pubescência esbranquiçada (Fig. 1). Pontuação elitral grossa e uniforme. Ápices elitrais leve e obliquamente truncados. Pernas e face ventral castanho-avermelhadas, com pubescência esbranquiçada.

Dimensões, em mm. Comprimento total, 5,8; comprimento do protórax, 1,1 ; maior largura do protórax, 2,0; comprimento do élitro, 4,3; largura umeral, 2,3.

Material-tipo. Holótipo fêmea, BRASIL, Rio Grande do Sul: Osório, 4.I.1950, P. Buck col. (MZSP)

Discussão. Nesozineus osorioensis sp. nov., pode 
ser incluída no grupo de espécies com élitros onde a pubescência não oblitera grande parte do tegumento. Pelos élitros com o terço apical contrastante com o restante do tegumento, assemelha-se a $N$. amazonicus Martins \& Galileo, 2010. Difere pelos espinhos laterais do protórax mais longos e mais aguçados; pelos élitros com faixa de pubescência esbranquiçada junto à sutura da base ao meio e pela declividade apical dos élitros normalmente abaulada. Em N. amazonicus, os espinhos laterais do protórax são cônicos; os élitros têm faixa longitudinal de tegumento amarelado sob os úmeros e a declividade apical é acentuada (Martins \& Galileo, 2010, fig. 1).

\section{Calliini \\ Drycothaea clara sp. nov. (Fig. 2)}

Etimologia. Latim, clarus = claro; alusivo à coloração geral.

Tegumento castanho-escuro. Corpo com pubescência predominante acinzentada. Cabeça com pubescência intercalada por pontos esparsos na fronte e entre os lobos oculares superiores. Lobos oculares desenvolvidos, os lobos inferiores com o quádruplo do comprimento das genas, distância entre os lobos superiores subigual à largura de um lobo. Antenas quebradas no ápice do antenômero V. Escapo com pontos contrastantes, esparsos. Antenômeros III-V com pubescência acinzentada, escurecidos na metade apical.

Protórax com pubescência, lateralmente mais densa, intercalada por pontos grossos, contrastantes e esparsos. Lados do protórax com espinho diminuto no meio. Prosterno liso. Processo mesosternal com quilha projetada, centro-longitudinal. Metasterno com pontos rasos e esparsos.

Escutelo com pubescência densa, não contrastante com a do élitro. Élitros com pubescência uniforme; mancha de pubescência mais densa no sexto apical (Fig. 2). Pontuação elitral não organizada em fileiras, esparsa no dorso da metade anterior e mais concentrada nos lados.

Fêmures com pontos contrastantes. Os metafêmures alcançam o meio do urosternito IV.

Urosternitos com pontos contrastantes, mais concentrados no urosternito $\mathrm{V}$.

Dimensões, em mm. Comprimento total, 11,6; comprimento do protórax, 2,1; maior largura do protórax, 3,0; comprimento do élitro, 8,4; largura umeral, 3,9.

Material-tipo. Holótipo fêmea, BRASIL, Rondônia: Porto Velho (Rio Madeira, $9^{\circ} 26^{\prime}$ S, $64^{\circ} 48^{\prime} \mathrm{W}$ ), 17-30.VI.2011, R. R. Silva et al. (MZSP).

Discussão. Na chave para as espécies de Drycothaea (GAlileo \& MARTins, 2010), D. clara é discriminada no item 18 que reza "Élitros com pontuação muito esparsa" juntamente com D. gaucha Galileo \& Martins, 2006.

Drycothaea clara sp. nov. caracteriza-se, principalmente, pela pubescência elitral acinzentada, uniforme, com pequena mancha, no sexto apical, de pubescência mais densa; pelos pontos dos élitros desalinhados, esparsos no dorso da metade anterior e mais concentradas nos lados e pelos antenômeros III-V escurecidos na metade apical. Comparada com $D$. gaucha Galileo \& Martins, 2008, que também apresenta pontuação elitral desuniforme, difere pelo tegumento castanho-escuro a preto, pelos pontos dos élitros mais numerosos, pequenos e profundos e pelo tubérculo mesosternal, glabro e estreito. Em D. gaucha (GAlileo \& MarTins, 2008, fig.1), o tegumento é avermelhado, a pubescência elitral é uniforme sem constituir áreas mais densas, os pontos elitrais são mais esparsos em direção ao ápice e o tubérculo mesosternal é menos saliente e arredondado.

\section{Drycothaea hovorei sp. nov. (Fig. 3)}

Etimologia. O nome específico é uma homenagem póstuma a Frank T. Hovore, coletor do holótipo.

Tegumento castanho-escuro na cabeça; tórax e élitros, castanho-avermelhados. Fronte esparsamente pontuada (20x), revestida por pubescência esparsa, acastanhada. Região entre os lobos oculares superiores esparsamente pontuada. Lobos oculares superiores com oito fileiras de omatídios; tão distantes entre si quanto o dobro da largura de um lobo. Antenas castanho-escuras; aproximam-se, mas não atingem o ápice dos élitros.

Espinho lateral do protórax evidente e aguçado. Pronoto densa e fortemente pontuado; revestidos por pubescência acastanhada. Tubérculo mesosternal pequeno e aguçado, restrito à base do processo mesosternal. Metasterno liso. Escutelo coberto por pubescência acastanhada, não contrastante com a dos élitros.

Élitros (Fig. 3) densa e finamente pontuados; pontos do dorso organizados em fileiras longitudinais; pelos abundantes e curtos; ápices arredondados.

Face ventral do corpo com pubescência castanhoamarelada.

Dimensões em mm. Comprimento total, 11,3; comprimento do protórax, 2,1; maior largura do protórax, 3,1; comprimento do élitro, 8,3; largura umeral, 3,8.

Material-tipo. Holótipo fêmea, EQUADOR, Napo: Arajuno (3 km N), 29.VIII.2004, F. T. Hovore col. (CASC).

Discussão. Drycothaea hovorei sp. nov. pode ser comparada com D. viridescens (Buquet, 1857) pelos élitros com pubescência unicolor e com pontuação densa e pontos dorsais alinhados; pelo escutelo sem pubescência contrastante com a da base dos élitros e pelos fêmures pretos. $\mathrm{Na}$ chave para as espécies de 
Drycothaea (GALILEO \& MarTins, 2010), esse conjunto de caracteres conduz ao item 22, onde são discriminadas D. estola (Lameere, 1893) e D. viridescens (Buquet, 1857).

Distingue-se de $D$. viridescens pela pontuação do pronoto regular e os pontos muito menores; pela pubescência elitral acastanhada e pelo tubérculo mesosternal aguçado. Em D. viridescens (Buquet, 1857) a pontuação do pronoto é profunda e desuniforme; a pubescência elitral é amarelada e o tubérculo do mesosterno é arredondado no topo. Distingue-se de $D$. estola pelos élitros densa e finamente pontuados. Em D. estola a pontuação é grossa e os pontos são mais separados entre si.

\section{Forsteriini Itacolomi gen. nov.}

Espécie-tipo: Itacolomi letiziae sp. nov.

Etimologia. Tupi, itacolomi $=$ pico nas imediações de Ouro Preto, MG; de itá-curumi, menino de pedra, nome da localidade-tipo. Gênero masculino.

Fronte transversal. Vértice convexo. Genas curtas com borda arredondada. Tubérculos anteníferos pouco projetados. Olhos com granulação grossa. Lobos oculares superiores com quatro fileiras de omatídios; tão distantes entre si quanto o dobro da largura de um lobo. Lobos oculares inferiores igual a 2,4 vezes o comprimento da gena. Antenas alcançam o ápice elitral, aproximadamente, na base do XI. Escapo mais curto que o antenômero III, subfusiforme, estreitado na base. Flagelômeros subcilíndricos; antenômero IV apenas mais longo que o III; comprimento dos antenômeros seguintes gradualmente decrescente.

Protórax mais largo que longo; lados com espinho curto, central. Protórax convexo. Processo prosternal estreitado entre as procoxas. Processo mesosternal com terço da largura da mesocoxa.

Élitros com os úmeros arredondados, pouco projetados anteriormente; margens laterais paralelas, ápice elitral arredondado. Superfície com pelos eretos.

Fêmures fusiformes; protíbias pouco alargadas no terço apical; mesotíbias com sulco profundo no centro. Metatarsômero I subigual ao comprimento do II+III.

Urosternitos com comprimento decrescente para o ápice.

Discussão. Itacolomi gen. nov. assemelha-se a Bactriola Bates, 1885, Falsamblesthis Breuning, 1959, Saepiseuthes Thomson, 1868 que também apresentam o ápice elitral arredondado. Itacolomi gen. nov. distinguese desses três gêneros pelo antenômero IV apenas mais longo que o III; nos outros gêneros, antenômero IV nitidamente mais longo que o III. Difere de Bactriola pelo protórax com espinho lateral; de Saepiseuthes pela base dos élitros sem crista e, de Falsamblesthis, pelas dimensões menores, pelos lobos oculares superiores com quatro fileiras de omatídios e pela cabeça sem pubescência clara e contrastante entre os tubérculos anteníferos. Em Bactriola, os lados do protórax são desarmados; em Saepiseuthes os élitros têm crista centrobasal e, em Falsamblesthis, as dimensões são maiores (em média, 12,5 mm) e os lobos oculares superiores têm, no mínimo, seis fileiras de omatídios.

\section{Itacolomi letiziae sp. nov.} (Fig. 4)

Etimologia. Nome específico homenageia Letizia Migliori (MZSP), coletora do holótipo.

Tegumento castanho-avermelhado, esternos torácicos e fêmures pretos. Fronte e vértice com pontuação grossa e pubescência castanho-amarelada entre os pontos. Antenas com pubescência acastanhada e pelos pretos na margem interna, estes tão longos quanto à largura dos artículos.

Pronoto com pontuação densa; pubescência castanho-amarelada disposta transversalmente nos lados e confluente para o centro. Escutelo coberto por pubescência amarelada.

Élitros densamente pontuados; com pubescência castanho-amarelada intercalada por manchas irregulares de pubescência mais alongada e esbranquiçada (Fig. 4).

Pernas revestidas por pubescência castanhoamarelada, esparsa.

Dimensões, em mm. Comprimento total, 5,4; comprimento do protórax, 1,0; maior largura do protórax, 1,2; comprimento do élitro, 3,8; largura umeral, 1,5; comprimento dos antenômeros: III, 0,6; IV, 0,7.

Material-tipo. Holótipo fêmea, BRASIL: Minas Gerais: Itacolomi $\left(20^{\circ} 25^{\prime} 55^{\prime}\right.$ 'S, 4329'45”W), 15-17.XI.2010, L. Migliori col., guarda-chuva entomológico (MZSP).

\section{Yapyguara gen. nov.}

Espécie-tipo: Yapyguara fusca sp. nov.

Etimologia. Tupi, yapyguara $=$ sertanejo; indivíduo que mora nas cabeceiras dos rios. Gênero feminino.

Fronte transversal. Região entre os tubérculos anteníferos aplanada. Vértice convexo. Mandíbulas com ápice entalhado. Tubérculo anteníferos pouco projetados. Olhos com granulação subgrossa. Lobos oculares superiores com cinco fileiras de omatídios; distância entre os lobos oculares igual ao dobro da largura de um lobo nos machos e cerca do triplo nas fêmeas. Lobos oculares inferiores com o triplo do comprimento da gena. Antenas, nos machos, aproximadamente tão longas quanto o corpo e, nas fêmeas, atingem o terço apical dos élitros. Escapo subcilíndrico, comprimento igual a 0,6 e 0,5 vezes o do III, macho e fêmea respectivamente. Antenômero III mais longo (1,3 vezes) que o IV; antenômeros V-XI com comprimento decrescente.

Lados do protórax arredondados, abaulados no terço basal. Pronoto convexo no meio, constrição 
basal acentuada. Processo prosternal estreitado entre as procoxas. Mesosterno transversalmente deprimido à frente do processo, com um terço da largura da mesocoxa.

Élitros com os úmeros arredondados, margens laterais subparalelas, sétimo apical em declive acentuado, com os lados estreitados e aplanados; ápice elitral obliquamente truncado da sutura para a margem.

Pernas curtas, metafêmures alcançam o meio do urosternito II; fêmures subfusiformes; tíbias tão longas quanto os fêmures; mesotíbias com sulco pouco profundo no nível do meio; metatarsômero I tão longo quanto o II e III em conjunto. Dente interno das garras tarsais curto.

Discussão. Yapyguara gen. nov. assemelha-se a Pseudogisostola Fontes \& Martins, 1977 pelo protórax sem espinho lateral e mandíbulas com ápice entalhado, mas difere pela distância entre os lobos oculares superiores igual ou maior que o dobro da largura de um lobo; pelo escapo subcilíndrico; pelo antenômero III mais longo que o IV, pelo dente interno das garras tarsais curto e pelo sétimo apical dos élitros abruptamente estreitados. Em Pseudogisostola, os lobos superiores são apenas mais distantes entre si do que a largura de um lobo, o escapo é engrossado para o ápice, o antenômero III é mais curto do que o IV, o dente interno das garras tarsais é mais longo e o ápice elitral é normalmente estreitado para o ápice.

\section{Yapyguara fusca sp. nov. (Fig. 5)}

Etimologia. Latim, fuscus $=$ moreno; alusivo ao colorido corporal.

Tegumento em geral castanho-avermelhado. Cabeça revestida de pubescência alongada, esbranquiçada; pontuação densa. Antenas castanho-avermelhadas; terço basal dos antenômeros IV-X castanho-amarelado.

Lados do protórax e pronoto com pubescência esbranquiçada; no pronoto, mais concentrada nos lados. Pontuação do pronoto densa, pontos grossos, justapostos. Escutelo revestido por pubescência esbranquiçada.

Élitros (Fig. 5) com pubescência esbranquiçada, mais adensada na declividade basal e na declividade apical; no restante da superfície, pubescência esparsa, entre os pontos. Pontuação elitral grossa, pontos justapostos.

Pernas revestidas por pubescência esbranquiçada; sulco das metatíbias, margem interna do quarto apical das protíbias e do terço apical das metatíbias, com pubescência acastanhada.

Face ventral coberta por pubescência esbranquiçada; densamente pontuada.

Dimensões, em mm, macho/fêmea. Comprimento total, 6,4/7,0; comprimento do protórax, 1,2/1,3; maior largura do protórax, 1,4/1,4; comprimento do élitro, 4,7/5,4; largura umeral, 1,6/1,7.
Material-tipo. Holótipo macho, BOLÍVIA, Santa Cruz Buena Vista (4-6 km SSE, Flora \& Fauna Hotel), 3-8.X.2004, Wappes \& Morris col. (MNKM); parátipo fêmea, mesmos dados do holótipo (ACMS).

\section{Xenofreini \\ Xenofrea zischkai sp. nov.}

(Fig. 6)

Etimologia. Nome específico homenageia postumamente R. Zischka, coletor de um dos parátipos.

Cabeça com tegumento preto. Fronte e região entre os tubérculos anteníferos revestidos por pubescência esbranquiçada, densa; genas e vértice com pubescência ocre; pontuação fina. Lobos oculares superiores com oito fileiras de omatídios; distância entre os lobos oculares superiores igual a 1,75 vezes a largura de um lobo. Antenas alcançam o ápice elitral no terço apical do IX aproximadamente. Escapo subcilíndrico, revestido por pubescência densa, entremeada por pontos, ocre na face dorsal e esbranquiçada na ventral. Comprimento dos antenômeros III e IV subigual. Antenômero III com pubescência amarelada mais esparsa. Base dos antenômeros IV-X com fina pubescência esbranquiçada e escurecidos na metade apical

Lados do protórax com gibosidade atrás do meio e pequeno alargamento junto à borda anterior, revestidos por pubescência ocre. Pronoto revestido por pubescência ocre com mancha, irregular, de pubescência esbranquiçada no centro. Pontuação pronotal fina, densa. Escutelo com pubescência ocre nos lados e estreita faixa centro-longitudinal glabra. Mesepisternos com pubescência branca na parte anterior e ocre na parte posterior. Metasterno com mancha de pubescência ocre, posterior e externa.

Base dos élitros (Fig. 6) com área triangular de pubescência ocre com manchas de pubescência acastanhada, pouco contrastantes: duas na declividade entre o escutelo e o úmero e outras duas centrais, atrás do escutelo. Faixa larga, oblíqua, da margem para a sutura, na área deprimida do terço basal, de pubescência fina, esbranquiçada; atrás dessa faixa, mancha lateral de pubescência acastanhada; uma faixa oblíqua, da sutura para a margem, de pubescência ocre que envolve pequena mancha de pubescência esparsa, esbranquiçada; terço apical com faixas alternadas de pubescência castanha e ocre. Pontuação elitral, na metade basal, grossa, anastomosada, mais fina e esparsa em direção ao ápice.

Fêmures revestidos por pubescência ocre na face dorsal e esbranquiçada nas laterais; pontos contrastantes em toda a superfície. Metafêmures dos machos com área dorsal deprimida, elíptica, revestida por pubescência branco-amarelada, uniforme. Protíbias dos machos com sulco glabro no lado interno.

Face ventral dos machos, com pelos brancos longos, abundantes nas pro- e mesocoxas, no centro do metasterno e dos urosternitos. Fêmeas com pilosidade ventral mais curta. 

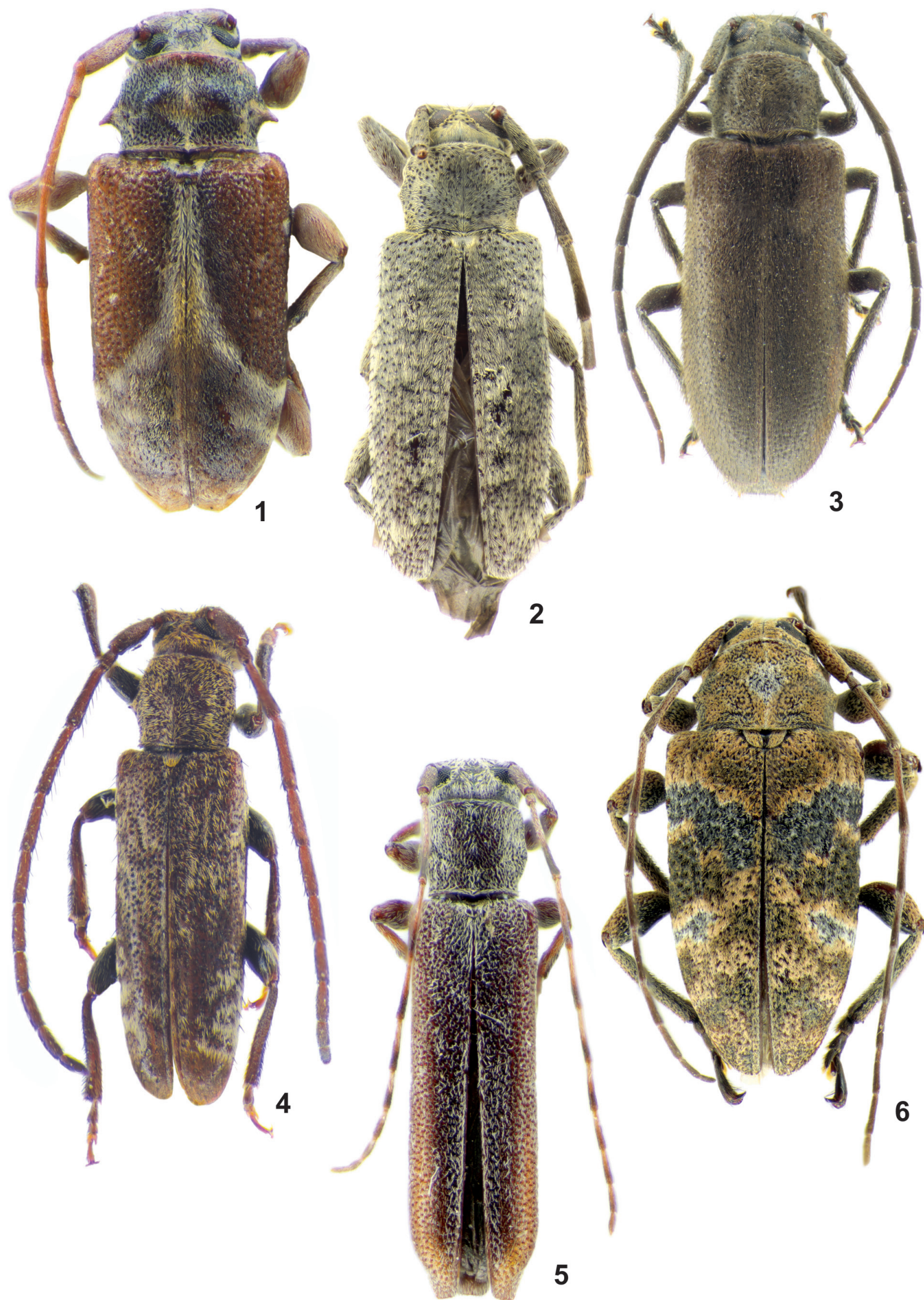

Figs 1-6. 1, Nesozineus osorioensis sp. nov., holótipo fêmea, comprimento total 5,8 mm; 2, Drycothaea clara sp. nov., holótipo fêmea, comprimento total 11,6 mm; 3, Drycothaea hovorei sp. nov., holótipo fêmea, comprimento total 11,3 mm; 4, Itacolomi letiziae sp. nov., holótipo fêmea comprimento total 5,4 mm; 5, Yapyguara fusca sp. nov., holótipo macho, comprimento total 6,4 mm; 6, Xenofrea zischkai sp. nov., parátipo fềmea, comprimento total $10,2 \mathrm{~mm}$. 
Dimensões, em mm, macho/fêmea. Comprimento total, 10,3-12,7/9,4-12,6; comprimento do protórax, 2,12,7/2,0-2,6; maior largura do protórax, 3,5-4,3/2,9-4,3; comprimento do élitro, 7,6-9,5/6,8-9,3; largura umeral, $4,8-6,0 / 4,0-5,7$.

Material-tipo. Holótipo macho, EQUADOR, Napo (Rio Napo - Rio Aguarico, 76-77ºW), IX-X.1977, L. Peña col. (MZSP) Parátipos: 2 fêmeas, mesmos dados do holótipo (MZSP); fêmea, BOLÍVIA, Santa Cruz: (600m), 2.IV.1960, Zischka col. (MZSP); macho, Buena Vista (3,7 km SSE, Hotel Flora \& Fauna, $430 \mathrm{~m}), 15-$ 21.XI.2001, B. K. Dozier col., black light, Transition Forest (ACMS); fêmea, (4-6 km SSE, Hotel Flora \& Fauna, 430 m), 1-8.XI.2002, J. E. Wappes col. (ACMS); fêmea, (5 km SSE, Hotel Flora \& Fauna, $440 \mathrm{~m}$, 17²9’96”S, 6339'13”W), 11.XII.2004, R. Clarke \& Zamalloa col., MU/UV light (RCSZ)

Discussão. Xenofrea zischkai sp. nov. assemelhase a $X$. magdalenae Neouze \& Tavakilian, 2005 pelo padrão dos élitros, destacando-se a faixa larga, oblíqua, da margem para a sutura, de pubescência fina, esbranquiçada na área deprimida do terço basal e mancha de pubescência branca, circundada por pubescência ocre, atrás do meio dos élitros, mas difere pelo pronoto revestido por pubescência ocre com mancha, irregular, de pubescência esbranquiçada no centro. Em $X$. magdalenae, o pronoto tem faixas longitudinais, uma no centro e a cada lado, de pubescência amarelada. Nos machos de $X$. magdalenae, os metafêmures não apresentam áreas deprimidas e revestidas por pubescência esbranquiçada que são conspícuas nos machos de X. zischkai.

Agradecimentos. A Larry Bezark (CASC), James Wappes (ACMS, MNKM) pelo envio de material para estudo. A Eleandro Moysés (Bolsista PIBIC-CNPq, Fundação Zoobotânica do Rio Grande do Sul) pelas ilustrações. Ao CNPq pela bolsa de pesquisa.

\section{REFERÊNCIAS BIBLIOGRÁFICAS}

Galileo, M. H. M. \& Martins, U. R. 1996. Revisão do gênero Nesozineus Linsley \& Chemsak, 1966 (Acanthoderini). Revista Brasileira de Entomologia 40(1):41-46.

2005. Novas espécies e novas ocorrências de Xenofrea (Lamiinae). Iheringia, Série Zoologia 95(4):383-388 2006. Novos táxons em Hippopsini, Desmiphorini, Xenofreini e Acanthoderini (Coleoptera, Cerambycidae, Lamiinae). Papéis Avulsos de Zoologia 46(3):21-29.

2007. Notas e descrições em Acanthoderini (Coleoptera, Cerambycidae, Lamiinae). II. Espécies novas do gênero Nesozineus. Revista Brasileira de Zoologia 24(3):631-634. 2008. Espécies novas de Calliini e Falsamblesthiini (Coleoptera, Cerambycidae, Lamiinae) da Região Neotropical. Revista Brasileira de Entomologia 52(1):32-35.

2010. Gênero Drycothaea (Coleoptera, Cerambycidae, Lamiinae): chave para espécies, nova combinação, espécies novas. Papéis Avulsos de Zoologia 50(5):69-75.

Martins, U. R. \& Galileo, M. H. M. 2010. Novas espécies de Lamiinae (Cerambycidae) neotropicais e transferência de Palpicrassus Galileo \& Martins, 2007. Papéis Avulsos de Zoologia 50(44):681-691.

Martins, U. R; Galileo, M. H. M. \& Limeira-de-Oliveria, F. 2009. Cerambycidae (Coleoptera) do estado de Maranhão, Brasil II. Papéis Avulsos de Zoologia 49(38):503-527. 